\title{
A Short Cylinder Ultrasonic Motor with Novel Excitation Mode
}

\author{
K.T. Chau, Bin Shi \\ Department of Electrical and Electronic Engineering \\ The University of Hong Kong \\ Hong Kong, China \\ ktchau@eee.hku.hk
}

\author{
Long Jing, Min-Qiang Hu, Ying Fan \\ Department of Electrical Engineering \\ Southeast University \\ Nanjing, China
}

\begin{abstract}
This paper presents a short cylinder ultrasonic motor, which is featured by its new structure and novel excitation mode. The stator is composed of two piezoelectric disks and two short cylindrical blocks in which the disks are sandwiched by the blocks to form a special bolted Langevin type transducer. The corresponding vibrations are utilized to produce the driving force. A novel excitation mode is realized which can solve the problem of instability occurred in the conventional excitation mode. By using finite element analysis, the vibration pattern and driving mechanism are simulated. Finally, the proposed motor and its driving circuitry are prototyped to experimentally verify its validity and performance.
\end{abstract}

Keywords-Excitation; piezoelectric; short cylinder; ultrasonic motor

\section{INTRODUCTION}

Ultrasonic motors (USMs) are a new class of electric motors, which are fundamentally different from common electromagnetic motors. Their principle of operation is based on the mechanical vibration of piezoelectric ceramics in the ultrasonic range (over $20 \mathrm{kHz}$ ) as the driving force [1]-[3].

The earliest research into an ultrasonically driven motor was conducted by Barth in 1973. Since Sashida originally developed the first USM in 1982 [1], the USM is becoming attractive for mechatronic applications because of its high torque density (about 1.1-8.8 Nm/kg), quiet operation (ultrasonic frequency range), high holding torque (almost maximum torque), quick response (about $1 \mathrm{~ms}$ ), and no electromagnetic interference.

In recent years, research and development of USMs have been focused on three main areas:

- Modeling approaches: Since the operating principle of USMs is fundamentally different from that of electromagnetic motors, the available modeling approaches for electromagnetic motors become ill-suited. Thus, the modeling of various USMs has been actively conducted [4][6].

- Control approaches: Many researchers have focused on designing the motion controllers which might not require their analytical models. Those motion control schemes are essentially based on adaptive control, fuzzy logic control, neural network control and/or neuro-fuzzy control [7]-[9].

- Motor design: Along with the rapid development of microelectromechanical systems, the miniaturization of USMs is being actively investigated such as the development of standing-wave stepping USMs [10]-[12] and the development of short cylinder USMs [13]-[15].

The first short cylinder USM was reported in 1989. It utilizes the principle of circular bending vibration or so-called the turning head traveling waves [13]. This motor is small in size and exhibits high mechanical output power. Compared with the conventional traveling wave USM in which the wave motion is damped when the elastic stator is held tightly, the short cylinder USM can be mounted firmly since its vibration pattern has nodes on the side of the cylinder and is hardly affected by being held at the nodes. Consequently, several improved versions of short cylinder USMs were proposed. In [14], a new arrangement for pressing the rotor against the vibration member was proposed, which can improve the output and efficiency of the motor. In [15], a corrugated tube horn and soft-type piezoelectric elements were newly adopted in the stator, which can notably widen the operating frequency range of the motor.

The purpose of this paper is to design and implement a new miniature short cylinder USM, hence achieving a compact positioning control system for military flight control. Comparing with the available short cylinder USMs [13]-[15], the proposed short cylinder USM offers a new structure and a novel excitation mode. Particularly, the corresponding excitation mode can solve the problem of instability occurred in the conventional excitation mode.

In Section II, the configuration of the newly designed short cylinder USM will be described. Emphasis will be given on the novelty of the excitation mode. In Section III, the corresponding principle of operation will be discussed. By using finite element analysis, the vibration pattern and driving mechanism will be simulated. Section IV will be devoted to present the implementation of this short cylinder USM. In Section V, experimental characteristics of the prototype will be given to verify its validity and performance. Finally, conclusions will be drawn in Section VI.

This work was supported and funded by a grant from Research Grants Council of Hong Kong Special Administrative Region, China. 


\section{MOTOR CONFIGURATION}

Fig. 1 shows the configuration of the proposed short cylinder USM which adopts a novel excitation mode. The stator consists of two piezoelectric disks made of lead zirconate titanate (PZT), and two short cylindrical blocks made of stainless steel. The PZT disks are sandwiched by the cylindrical blocks to form a special bolted Langevin type transducer, which has much more powerful output capability than the bonded transducer used in the conventional disk-type traveling wave USM. The stator is fixed on the mounting face through the elastic supported plate. The rotor made of aluminum alloy is pressed to the upper surface of the stator by a spring.

The division of the electrodes and the polarization of the PZT disks of this short cylinder USM are different from the available design arrangements. Fig. 2 and Fig. 3 illustrate two viable arrangements - one with two PZT disks [13] and another with four PZT disks [14], [15], respectively.

Fig. 2 shows the arrangement with two PZT disks which have the same polarization directions facing one and another. Each disk has four isolated electrodes. When high frequency sinusoidal voltage is applied to a pair of electrodes that are located diagonally, the bending vibration has two nodes along the axis of symmetry. The turning head traveling wave is produced by applying another pair of electrodes simultaneously with another sinusoidal voltage which is $90^{\circ}$ out of phase. On the other hand, Fig. 3 shows the arrangement with four PZT disks which form two pairs of excitations. Each disk has two isolated electrodes which have different polarization directions as indicated by ' + ' and ' - '. When inputting two sinusoidal voltages with a phase shift of $90^{\circ}$, the turning head traveling wave of bending vibrations is created.

In the proposed short cylinder USM, a novel arrangement of two PZT disks is introduced. As shown in Fig. 4, four isolated electrodes are manufactured at one side and the whole electrode is at the other side. The corresponding polarization direction is indicated by ' + ' and ' - '. Notice that when a high frequency sinusoidal voltage is applied between a pair of electrodes located diagonally and the whole electrode side, the transducer exhibits a vibration pattern along the shaft as shown in Fig. 5.

Due to the small length-to-diameter ratio of this short cylinder USM, the conventional excitation mode has a severe problem, namely the difficulties in stable operation and motor control. Although the problem can be alleviated by reducing the thickness of the PZT disk, the tradeoff is the reduction in output torque. In this paper, a novel excitation mode is proposed to solve this problem. As shown in Fig. 4, the PZT disk faces each other with the isolated electrodes in-between. The electrodes located diagonally are connected as one phase. The excitation position is always located at the central place of the phase. To increase the output torque of the motor, the corresponding increase in the thickness of the PZT disks will not cause the problem of instability occurred in the conventional excitation mode.

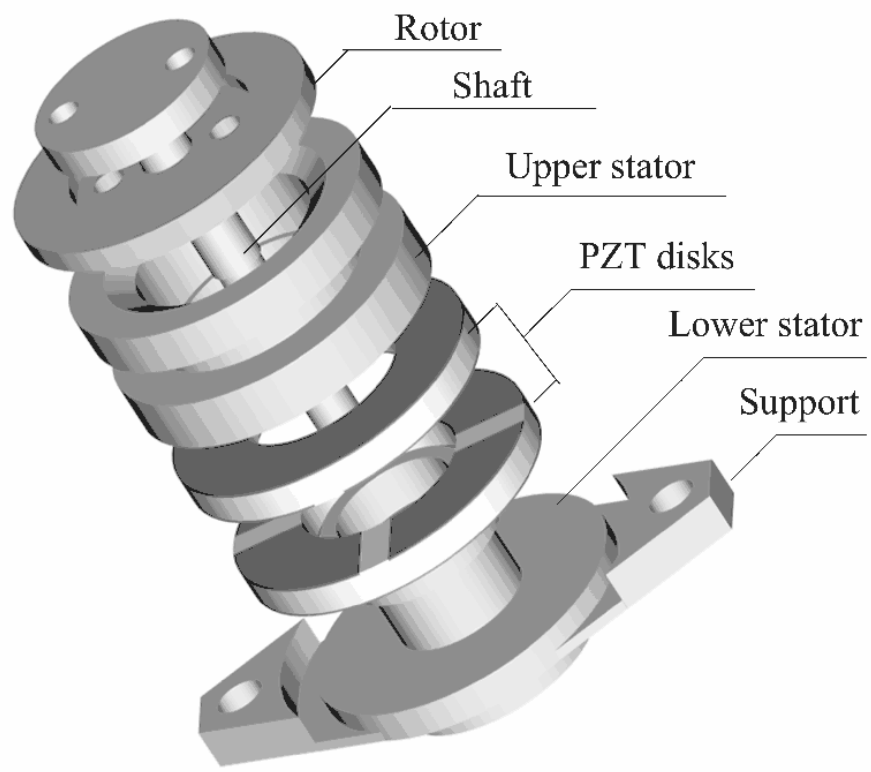

Figure 1. Proposed motor configuration.

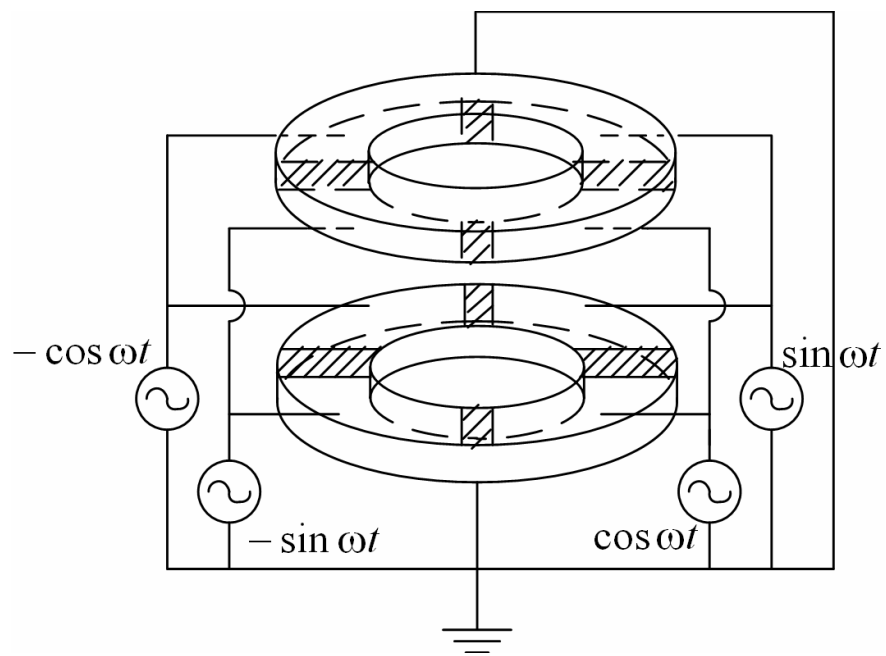

Figure 2. Available excitation mode with two PZT disks. 


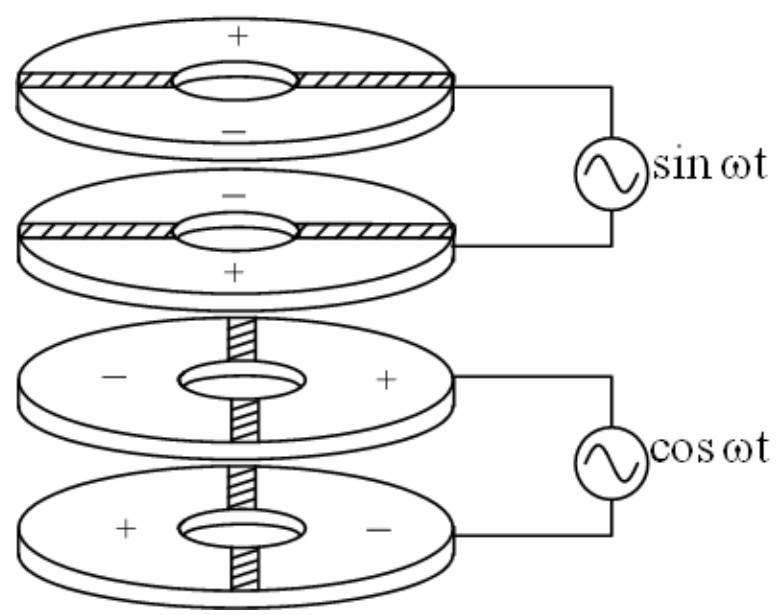

Figure 3. Available excitation mode with four PZT disks.

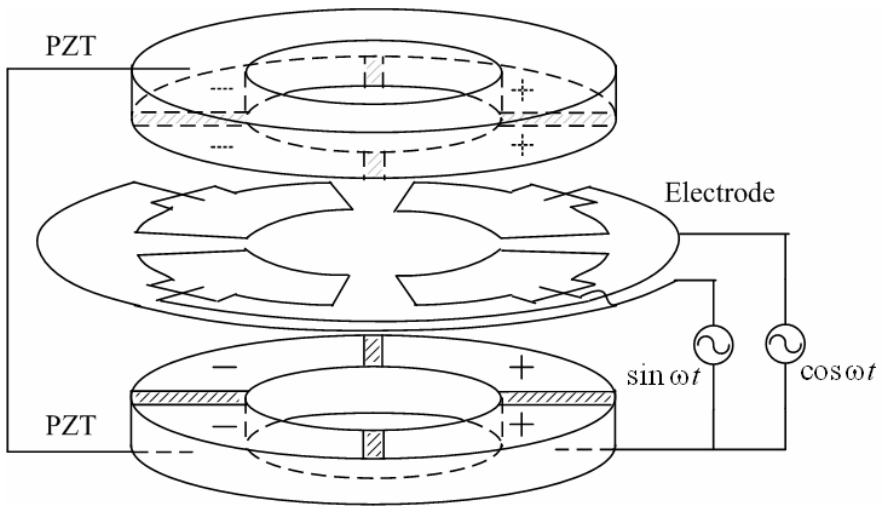

Figure 4. Proposed excitation mode.

\section{PRINCIPLE OF OPERATION}

The driving principle of this short cylinder USM is shown in Fig. 4. When a phase voltage is applied, the region located on the diagonal line of the upper PZT element and the underside one is excited at the same time. The stator vibrates in a vibration pattern along the shaft direction. The rotor keeps in contact with the outside of the upper disk surface of the stator. The two phases locate apart from each other with $90^{\circ}$ in spatial space. If they are driven by two-phase high frequency voltages with $90^{\circ}$ difference in time, the vibration will revolve about the shaft and the upside of the stator will vibrate as a flexural traveling wave. The flexural traveling wave vibration makes the surface point particle move in an elliptical way. Since the rotor is pressed against the stator upper side, the frictional force between them will drive the rotor continually.

In order to design the vibration pattern and hence to estimate the appropriate driving frequency, the vibration analysis is necessary. The finite element analysis based on a commercially available software package is utilized to perform this vibration analysis. The corresponding vibration pattern at a particular instant is depicted in Fig. 6. It can be seen that the first-order vibration is excited, and the estimated resonant frequency is $43.5 \mathrm{kHz}$. Furthermore, a series of vibration patterns at different instants are simulated. Hence, the driving mechanism of this short cylinder USM can be depicted as shown in Fig. 7.

It should be noted that the use of this estimated resonant frequency for practical driving may cause inevitable errors such as some unnecessary higher order vibrations. In order to further improve the driving effectiveness of this short cylinder USM, the driving frequency needs to be accurately determined. According to the general equivalent circuit of the USM, the resonant frequency can be directly obtained by using the impedance measurement of the stator. It can be found that the minimum value of the impedance occurs at the resonant frequency which should be adopted as the practical driving frequency.

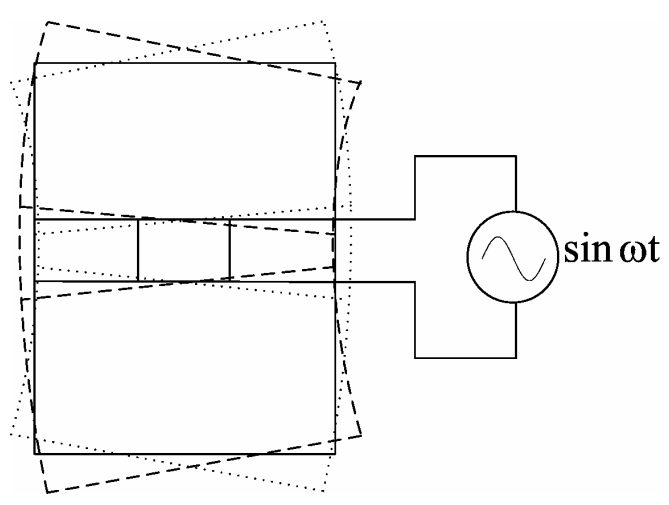

Figure 5. Proposed vibration pattern.

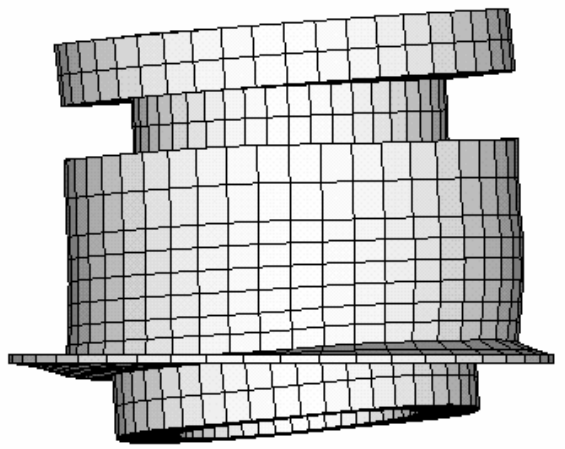

Figure 6. Simulated vibration pattern. 


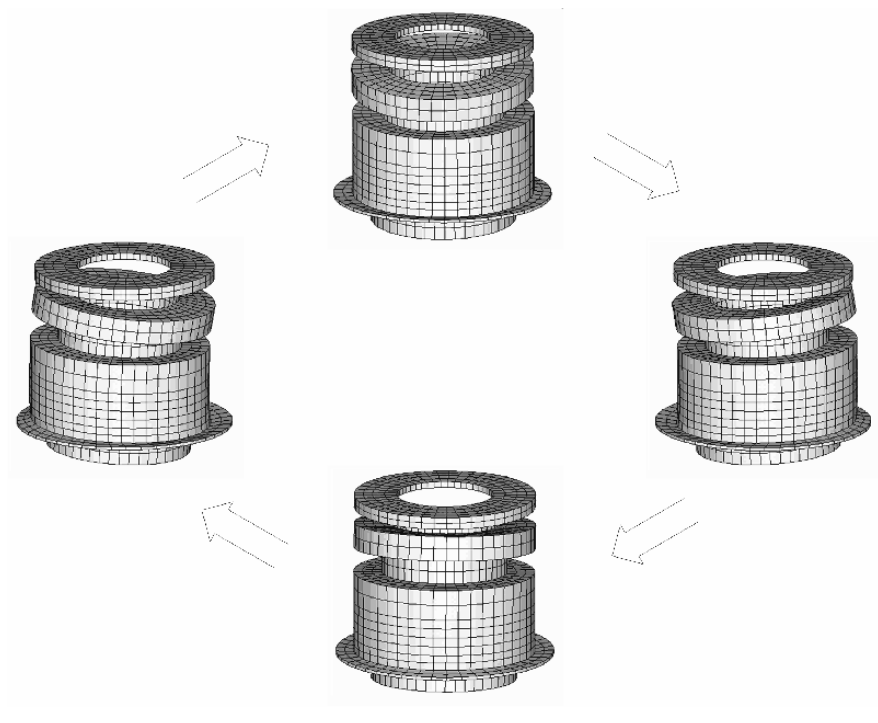

Figure 7. Simulated driving mechanism.

\section{IMPLEMENTATION}

According to the aforementioned configuration, the proposed short cylinder USM is prototyped. Its practical construction is shown in Fig. 8, in which the lower stator is fixed on the mounting face through the elastic supported plate. The end face of the upper stator is used to drive the contacted rotor. A shaft with a disk flange at one end applies an axial pressure to the rotor against the end face of the upper stator through the spring. The constricted portion (a circumferential groove) in the upper stator functions to amplify the vibration amplitude. Two bearings located at both ends of the lower stator function to ensure the shaft centered. The key parameters of the motor prototype are listed in Table I. A photo of two motor prototypes is shown in Fig. 9.

In order to drive the proposed short cylinder motor, the control circuit block diagram is shown in Fig. 10. The hardware core is the TMS320F240 microcontroller, which functions to receive the feedback information (speed and position) from the incremental position encoder, and to generate appropriate control signals in accordance with the position command. These control signals are then fed into the driving circuitry to power the USM. The experimental driving circuitry is shown in Fig. 11.

To evaluate its performance, the prototype is mounted onto a test-bed which functions to measure both the steady-state characteristics and transient responses. As shown in Fig. 12, a DC servo motor is worked as the dynamometer of the test-bed. After connecting an electronic load onto this dynamometer, a programmable load torque can be flexibly implemented for performance evaluation.
TABLE I. PARAMETERS OF MOTOR PROTOTYPE

\begin{tabular}{ll}
\hline Inner radius of upper stator & $9.0 \mathrm{~mm}$ \\
Outer radius of upper stator & $15.0 \mathrm{~mm}$ \\
Inner radius of lower stator & $8.0 \mathrm{~mm}$ \\
Outer radius of lower stator & $15.0 \mathrm{~mm}$ \\
Height of upper stator & $6.5 \mathrm{~mm}$ \\
Height of lower stator & $9.5 \mathrm{~mm}$ \\
Height of PZT disks & $1.5 \mathrm{~mm}$ \\
Inner radius of rotor & $11.0 \mathrm{~mm}$ \\
Outer radius of rotor & $15.0 \mathrm{~mm}$ \\
Height of rotor & $2.0 \mathrm{~mm}$ \\
Radius of shaft & $2.5 \mathrm{~mm}$ \\
Height of shaft & $22.5 \mathrm{~mm}$ \\
\hline
\end{tabular}

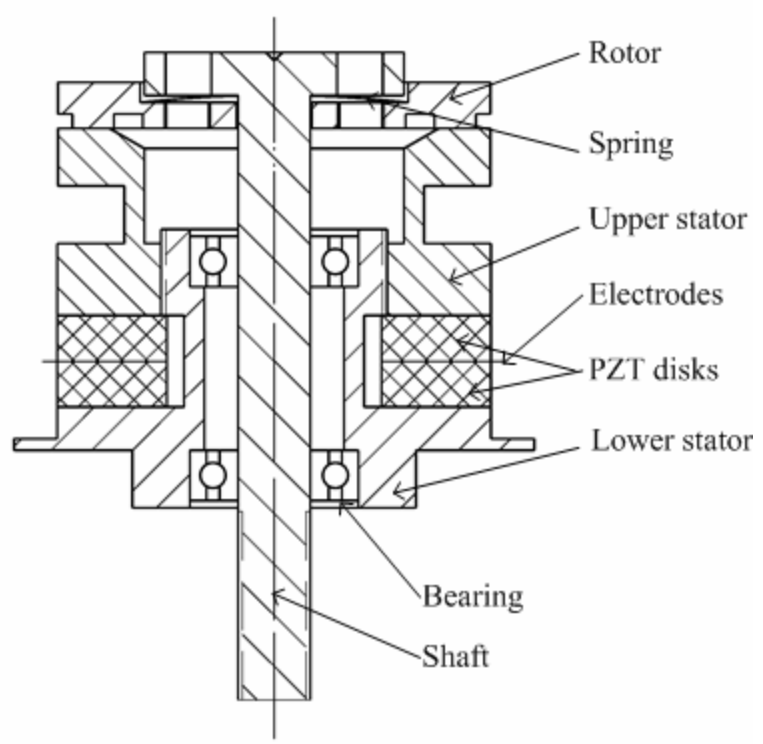

Figure 8. Motor construction.

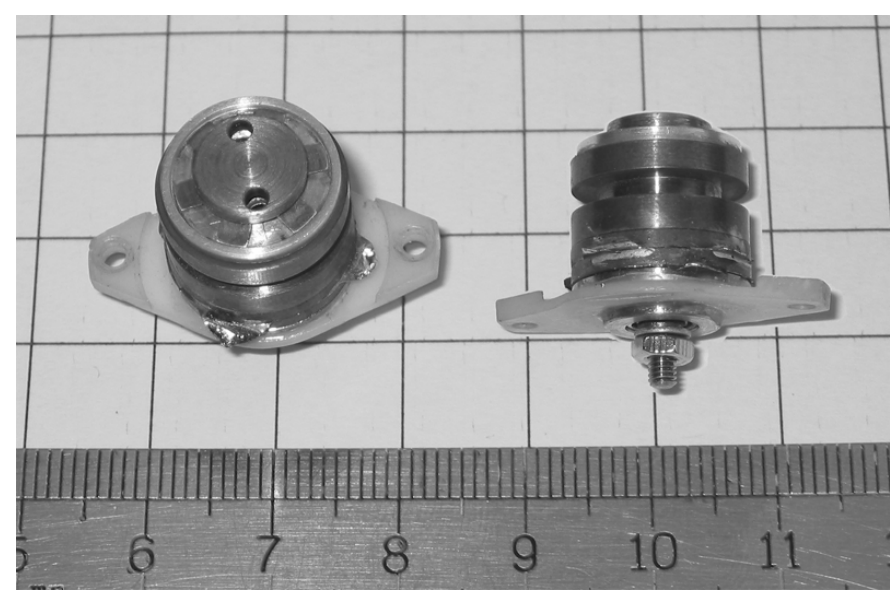

Figure 9. Motor prototype. 


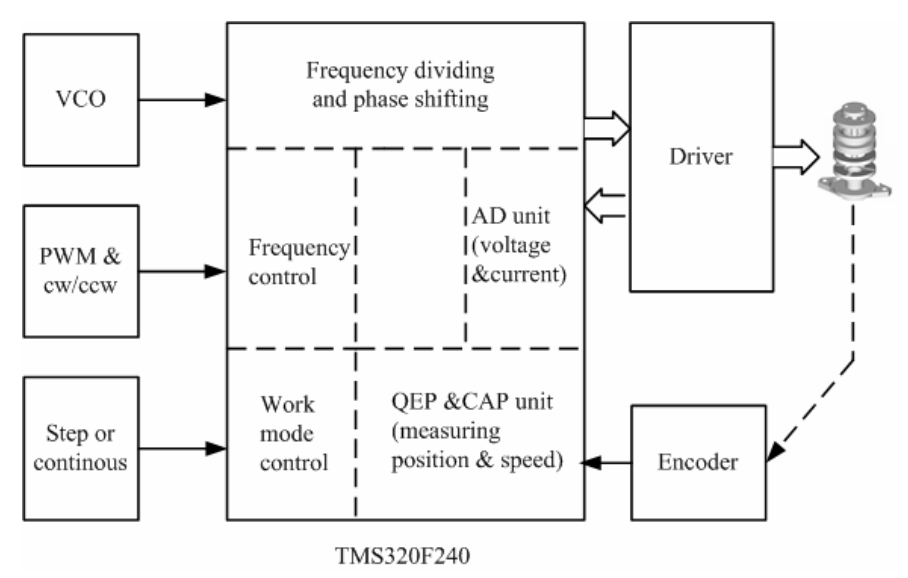

Figure 10. Control circuit block diagram.

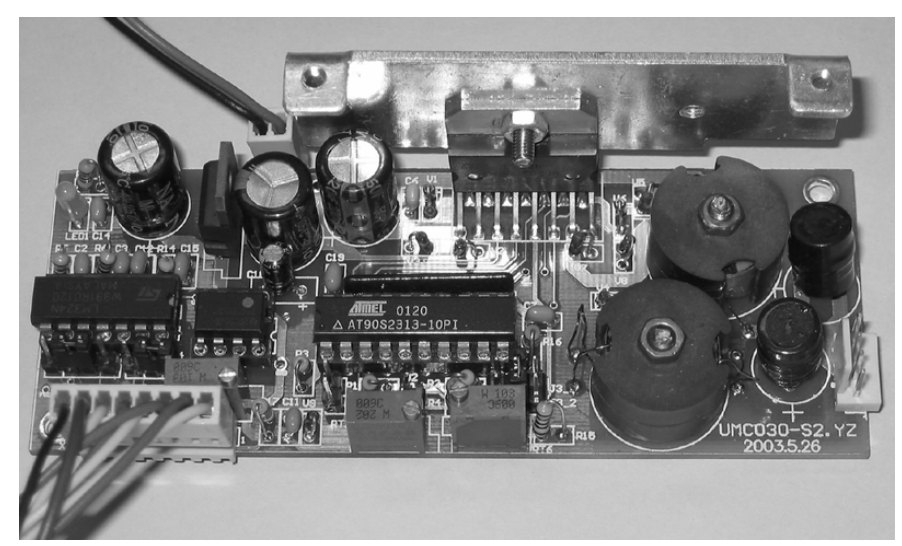

Figure 11. Driving circuit prototype.

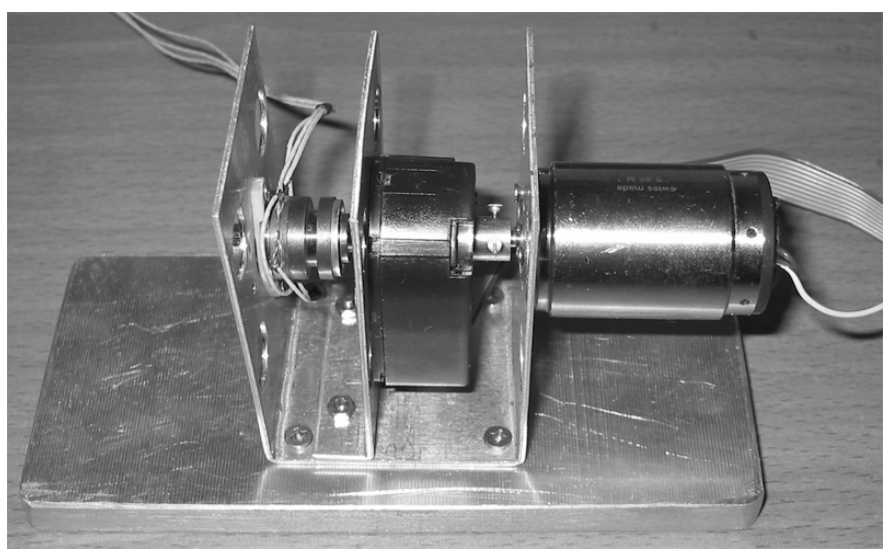

Figure 12. Test-bed.

\section{EXPERIMENTAL CHARACTERISTICS}

As mentioned before, the driving frequency can be accurately determined by directly measuring the impedance of the stator. Fig. 13 shows the recorded impedance of the stator with respect to the applied frequency. It can be found that the minimum value of the impedance occurs at the resonant frequency of $46.17 \mathrm{kHz}$ which will be adopted as the practical driving frequency.

By using the aforementioned test-bed, the relationship between the rotational speed and the applied frequency of the prototype is measured as shown in Fig. 14. It can be found that the proposed USM can work well at the frequency band of 45$47 \mathrm{kHz}$, and the change of applied frequency can successfully regulate the rotational speed. Moreover, in order to further assess the dynamic performance of this USM, the start-up and shut-down step responses within a short duration are recorded as shown in Fig. 15. It can be seen that the response time is very short, with the order of $10 \mathrm{~ms}$. Also, both the rise-up and fall-down curves are approximately linear.

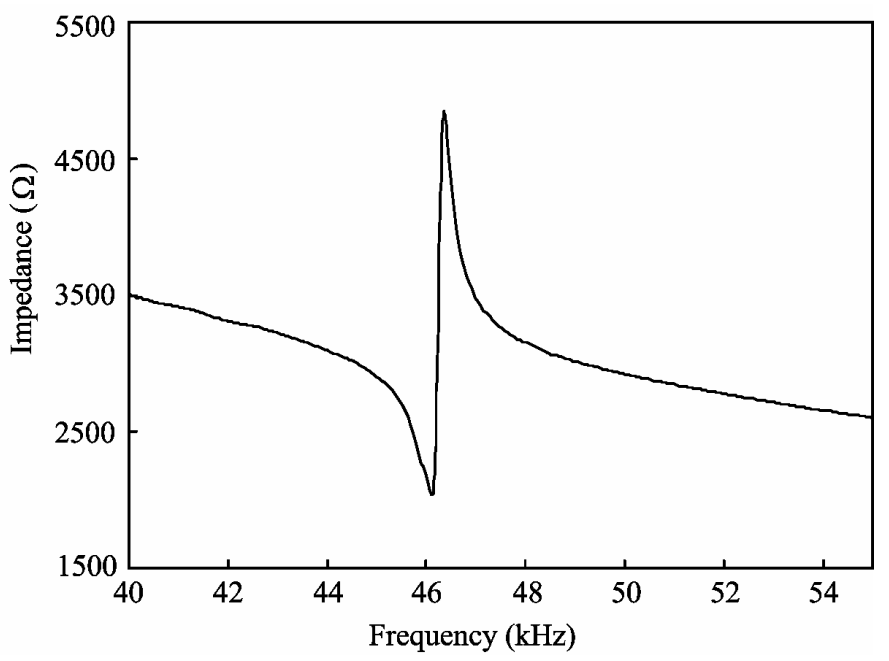

Figure 13. Measured stator impedance.

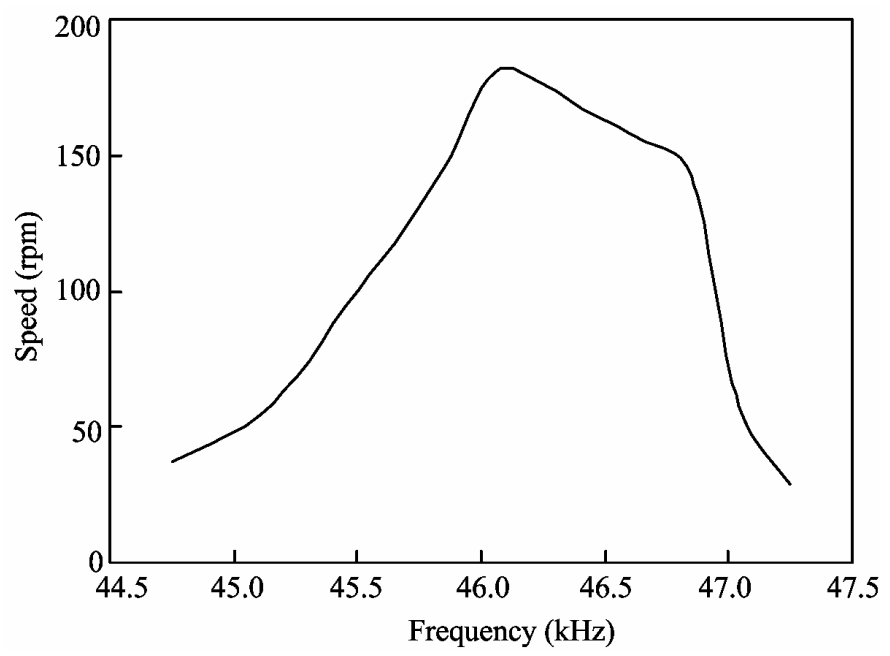

Figure 14. Measured speed-frequency characteristic. 


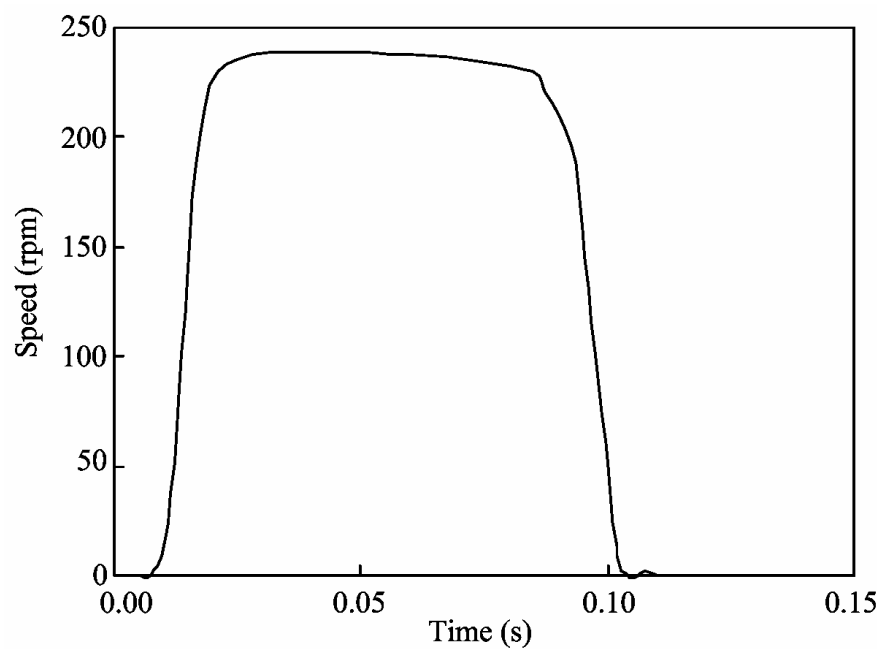

Figure 15. Measured start-up and shut-down responses.

\section{CONCLUSIONS}

In this paper, a new short cylinder USM has been proposed and implemented. This USM is characterized by a new structure and a novel excitation mode. Its stator is composed of two PZT disks and two short cylindrical blocks in which the disks are sandwiched by the blocks to form a special bolted Langevin type transducer. By applying two sinusoidal voltages with $90^{\circ}$ phase difference to the PZT disks, the resulting bending vibrations produce the turning head traveling wave and hence the driving force. The proposed excitation mode is realized which can solve the problem of instability that occurred in the conventional excitation mode. Both computer simulations using finite element analysis and experimental measurements confirm the validity and performance of the proposed short cylinder USM.

\section{REFERENCES}

[1] T. Sashida, and T. Kenjo, An Introduction to Ultrasonic Motors. New York: Oxford Science Publications, 1993.
[2] S. Ueha, and Y. Tomikawa, Ultrasonic motors: Theory and Applications. New York: Oxford Science Publications, 1993.

[3] K. Uchino, "Piezoelectric ultrasonic motors: overview," Smart Materials and Structures, Vol. 7, 1998, pp. 273-285.

[4] N.W. Hagood, and A.J. McFarland, "Modeling of a piezoelectric rotary ultrasonic motor," IEEE Transactions on Ultrasonics, Ferroelectrics and Frequency Control, Vol. 42, 1995, pp. 210-224.

[5] P. Helin, V. Sadaune, C. Druon, and J.B. Tritsch, "A mechanical model for energy transfer in linear ultrasonic micromotors using Lamb and Rayleigh waves," IEEE Transactions on Mechatronics, Vol. 3, 1998, pp. 3-8.

[6] P.A. Juang, and W. Brenner, "The transfer function of a new disc-type ultrasonic motor," Sensors and Actuators A, Vol. 100, 2002, pp. 272280.

[7] T. Senjyu, T. Kashiwagi, and K. Uezato, "Position control of ultrasonic motors using MRAC and dead-zone compensation with fuzzy inference," IEEE Transactions on Power Electronics, Vol. 17, 2002, pp. 265-272.

[8] K.T. Chau, and S.W. Chung, "Servo position control of ultrasonic motors using fuzzy neural network," Electric Machines and Power Systems, Vol. 29, 2001, pp. 229-246.

[9] K.T. Chau, S.W. Chung, and C.C. Chan, "Neuro-fuzzy speed tracking control of traveling-wave ultrasonic motor drives using direct pulse width modulation," IEEE Transactions on Industry Applications, Vol. 39, 2003, pp. 1061-1069.

[10] S. He, W. Chen, X. Tao, and Z. Chen, "Standing wave bi-directional linearly moving ultrasonic motor," IEEE Transactions on Ultrasonics, Ferroelectrics and Frequency Control, Vol. 45, 1998, pp. 1133-1139.

[11] A.E. Glazounov, S. Wang, Q.M. Zhang, and C. Kim, "Piezoelectric stepper motor with direct coupling mechanism to achieve high efficiency and precise control of motion," IEEE Transactions on Ultrasonics, Ferroelectrics and Frequency Control, Vol. 47, 2000, pp. 1059-1067.

[12] K.T. Chau, B. Shi, and M.Q. Hu, "A design method and half-step operation for ultrasonic stepping motors," IEEE Transactions on Industry Applications, Vol. 39, No. 4, 2003, pp. 953-960.

[13] M. Kurosawa, K. Nakamura, T. Okamoto, and S. Ueha, "An ultrasonic motor using bending vibrations of a short cylinder," IEEE Transactions on Ultrasonics, Ferroelectrics and Frequency Control, Vol. 36, 1989, pp. 517-521.

[14] T. Nishio, and H. Kanazawa, Vibration Driven Motor. U.S. Patent No. $5,973,439,1999$

[15] S. Dong, S. Wang, W. Shen, and L. Li, "A miniature piezoelectric ultrasonic motor based on circular bending vibration mode," IEEE/ASME Transactions on Mechatronics, Vol. 5, 2000, pp. 325-330. 